\title{
Ulrich Luz
}

\section{Exegetische Aufsätze}

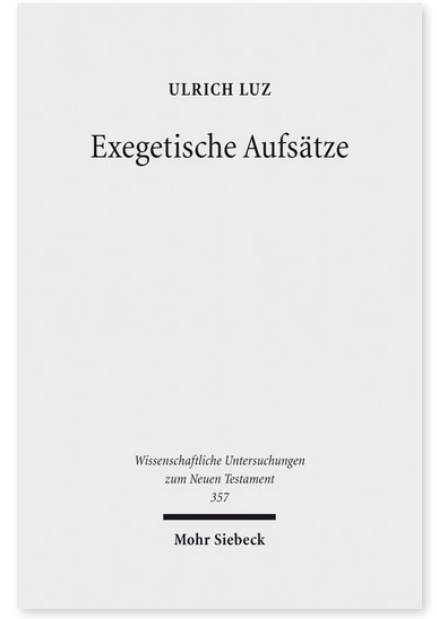

2016. IX, 565 Seiten. WUNT I 357

ISBN 978-3-16-154547-4

DOI 10.1628/978-3-16-154547-4

eBook PDF 209,00€

ISBN 978-3-16-153536-9

Leinen $209,00 €$
Ulrich Luz legt in diesem Band 32 exegetische Aufsätze vor, die fast alle zwischen 1985 und 2015 entstanden sind. Darunter sind fünf bisher ungedruckte und fünf weitere, bisher nicht in deutscher Sprache vorliegende Texte. Die Mehrzahl der Studien erscheinen in deutscher, einige in englischer Sprache. Ein erstes Kapitel enthält Aufsätze zu Jesus, ein zweites solche zur Logienquelle Q. Das dritte, längste Kapitel versammelt 10 Aufsätze zum Matthäusevangelium, dem wichtigsten Schwerpunkt der Forschungen von Luz. Ein kurzes, viertes Kapitel enthält zwei Aufsätze zum Markus- und zum Johannesevangelium. Das abschliessende fünfte Kapitel ist dem Corpus Paulinum gewidmet. Zu jedem Kapitel gehört eine Einleitung, welche in die Aufsätze einführt und sie evaluiert. Im Mittelpunkt des Jesuskapitels stehen weniger historische Fragen im engeren Sinn, sondern die Grundfrage, warum wir als Theologen nach dem sogenannten historischen Jesus fragen und unter welchen Prämissen wir dies tun. Im Matthäuskapitel geht es in vielen Aufsätzen hermeneutische Grundfragen: Wie können wir seine Jesus-Christusgeschichte von innen, d.h. als an ihr Beteiligte lesen? Welches Verständnis von »Wahrheit« setzt Matthäus voraus? Im Pauluskapitel stehen Fragen nach der Frömmigkeit des Paulus und nach seinem Verständnis von Rechtfertigung und Gericht im Vordergrund.

Ulrich Luz (1938-2019) 1957-62 Studium der Theologie in Zürich, Göttingen und Basel; 1970 Dozent für christliche Theologie und Neues Testament in Tokyo; 1972 o. Prof. für Neues Testament in Göttingen; 1980 o. Prof. für Neues Testament in Bern; 2003-19 Prof. emeritus.

\section{Jetzt bestellen:}

https://mohrsiebeck.com/buch/exegetische-aufsaetze-9783161545474?no_cache=1

order@mohrsiebeck.com

Telefon: +49 (0)7071-923-17

Telefax: $+49(0) 7071-51104$ 